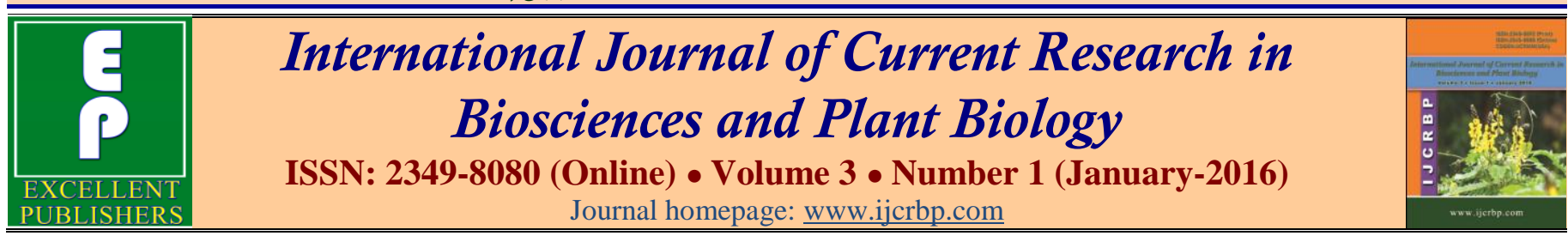

Original Research Article

doi: http://dx.doi.org/10.20546/ijcrbp.2016.301.013

\title{
Production of Biocement from Microalgae
}

\section{J. Jebamalar and Priya Iyer*}

P. G. and Research Department of Biotechnology, Women's Christian College, Chennai-6oo oo6, Tamil Nadu, India

*Corresponding author.

\begin{abstract}
Water samples were collected from Kovalam beach, Kovalam prawn hatchery, Ennore beach and N4 beach. Water sample was cultured in Walne's medium and Chu's medium to enhance the algal growth and ability of the algae to produce urease enzyme using M342 medium Water hardness is determined by titrating against EDTA. Urea hydrolysis was done on M342 medium to obtain best urea hydrolyzing algae and detecting urea tolerance levels of algae sample. Biocement was produced in-vitro by incubating it for two weeks and the precipitated biodeposition was filtered and air dried. The porosity of biomass was determined by Scanning Electron Microscope.
\end{abstract}

\section{Article Info}

Accepted: 14 December 2015

Available Online: 06 January 2016

Keywords

Biocement

Microalgae

Urea hydrolysis

\section{Introduction}

Biocement is a term coined by Dr. Cord Ruwisch of Murdoch University to describe the Calcium carbonate formed by soil based bacteria; Biocement, a self-healing material to enhance durability of building structures and conservation of cultural heritages. Numerous diverse species participate in the precipitation of mineral carbonates in various natural environments including soils, geological formations, freshwater biofilms, oceans and saline lakes. Recently, microbial mineral precipitation resulting from metabolic activities of some specific microorganisms in concrete to improve the overall behavior of concrete has become an important area of research. The use of this biomineralogy concept leads to the potential invention of a new material. Bacterial cement, are inherent and self-repairing biomaterial that can remediate the cracks and fissure in concrete. Though concrete is quite strong mechanically, it suffers from several drawbacks, such as low tensile strength, permeability to liquid and consequent corrosion of reinforcement, susceptibility to chemical attack and low durability (Ghosh et al., 2006). In the present study, the microalgae collected from water samples were assessed for biocement production.

\section{Materials and methods}

\section{Sample collection}

Water samples were collected from Kovalam beach, Kovalam prawn hatchery, Ennore beach and N4 beach.

\section{Isolation and Identification of algae}

Water sample collected was inoculated to Walne's medium and Chu's medium for growth of algae. The ability of the algae to produce urease enzyme was checked using M342 medium.

\section{Determination of water hardness by EDTA}

The sample was adjusted to pH10 using Sodium hydroxide buffer solution (or) conc. ammonia + ammonium chloride. Few drops of Eriochrome black $(0.5 \% \mathrm{wt} / \mathrm{vol})$ indicator was added and sample titrated against $0.01 \mathrm{M}$ EDTA. The total hardness of water sample is calculated using the precise of EDTA added when the indictor changes the color from red to blue. The calcium carbonate concentration was calculated 
according to the following equation:

$\mathrm{Ca}_{2} \mathrm{CO}_{3}=$ [Vol.EDTA (ml) / sample volume (L) X $\left[\mathrm{Ca}_{2} \mathrm{CO}_{3}\right.$ (1 Mol) / EDTA (Mol).

\section{Urea hydrolysis phase test}

M342 agar medium was inoculated with algae sample, urea and indicator and incubated for two days.

\section{Urea tolerance level of algae}

The urea hydrolyzing algal sample was added to $1.0,1.5$, $2.0,2.5,3.0,3.5$ and $4.0 \mathrm{M}$ urea concentration and incubated for 3 days under the light. The visual turbidity was determined at $600 \mathrm{~nm}$ using UV spectrophotometer

\section{Production of Biocement from Hard water and characterization}

Sea Water, urea $(3 \mathrm{M})$ and algae were mixed and incubated for 2 weeks. After incubation the deposits of calcium carbonate was filtered using normal filter paper and the filter paper with the deposits kept in hot air oven. The porosity of the biocement was determined by Scanning Electron Microscope.

\section{Application of the biocement}

Cracked plastic pumps were taken and biocement were applied on the cracks. A hole in the tube were sealed with biocement and biodeposition were made into bead like form and the string were inserted and allowed to dry to check the binding capacity

\section{Results and discussion}

\section{Growth of algae}

Growth of Chaetoceros calcitranswas found to grow in Walne's medium was observed after 14 days. The algae were identified microscopically. The maximum growth was obtained after 45 days. Growth of mixed culture sample in Chu's medium was observed after 21 days. The mass growth was after 1 month. Similar work was done by Banerjee et al. (2011) who cultured algae in outdoor to maintain the natural environment. In the present work algae sample was cultured in laboratory condition and the algae showed mass growth in indoor environment. In the study by Ilavarasi et al. (2011), freshwater microalgae were used in Chu's medium. However, in the present work sea water sample was used in Chu's medium which showed mass growth of microalgae.

\section{Urease test}

The M342 medium inoculated with the algae changed to pink color immediately after the addition of phenolphthalein ( $\mathrm{pH}$ indicator). Similar urease test was done by for microalgae and phenolphthalein indicator was added along with M342 medium (Patil and Mahajan, 2011). In this work, cultured microalgae was used and after inoculating the algae in M342 then added indicator without incubation sample produced pink color.

\section{Determination of hardness of water}

The EDTA draws the calcium and magnesium ions into a complex which is present in the water sample, so neither ion are free in the solution.

\section{Hardness in sea water}

\section{Kovalam sample:}

Volume of EDTA solution $\quad=\quad 50 \mathrm{ml}(\mathrm{V} 1)$

Strength of EDTA solution $=19.5 \mathrm{ml}(\mathrm{V} 2)$

Volume of sea water $\quad=\quad 20 \mathrm{ml}(\mathrm{NI})$

Strength of sea water $(\mathrm{N} 2)=\mathrm{VI}^{*} \mathrm{~N} 2 / \mathrm{NI}$

$$
50 * 19.5 / 20=48.75 \mathrm{mg} / \mathrm{ml}
$$

Total hardness in $20 \mathrm{ml}$ of sea water $=48.75 \mathrm{mg} / \mathrm{ml}$

\section{Ennore sample:}

Volume of EDTA solution $\quad=\quad 50 \mathrm{ml}(\mathrm{V} 1)$

Strength of EDTA solution $=25.3 \mathrm{ml}(\mathrm{V} 2)$

Volume of sea water $=20 \mathrm{ml}(\mathrm{NI})$

Strength of sea water $(\mathrm{N} 2)=\mathrm{VI} * \mathrm{~N} 2 / \mathrm{NI}$

$50 * 25.3 / 20=63.25 \mathrm{mg} / \mathrm{ml}$

Total hardness in $20 \mathrm{ml}$ of sea water $=63.25 \mathrm{mg} / \mathrm{ml}$

Some reports indicate that to determine the hardness of ground water Calmagite is used as indicator (Yappert and DuPre, 1997). In present study estimated the hardness of seawater using Eriochrome black $\mathrm{T}$ as indicator. Total hardness water higher in Ennore water than the Kovalam sample. Higher concentration of $\mathrm{Ca}^{2+}$ and $\mathrm{Mg}^{2+}$ in Ennore sample is due to industries near the beach.

\section{Urea hydrolysis phase test}

The algae samples were inoculated in M342 agar medium; the tubes were incubated under light for 3 days. A change of color in the medium from colorless to pink indicates the presence of urease enzyme (Fig. 1). 


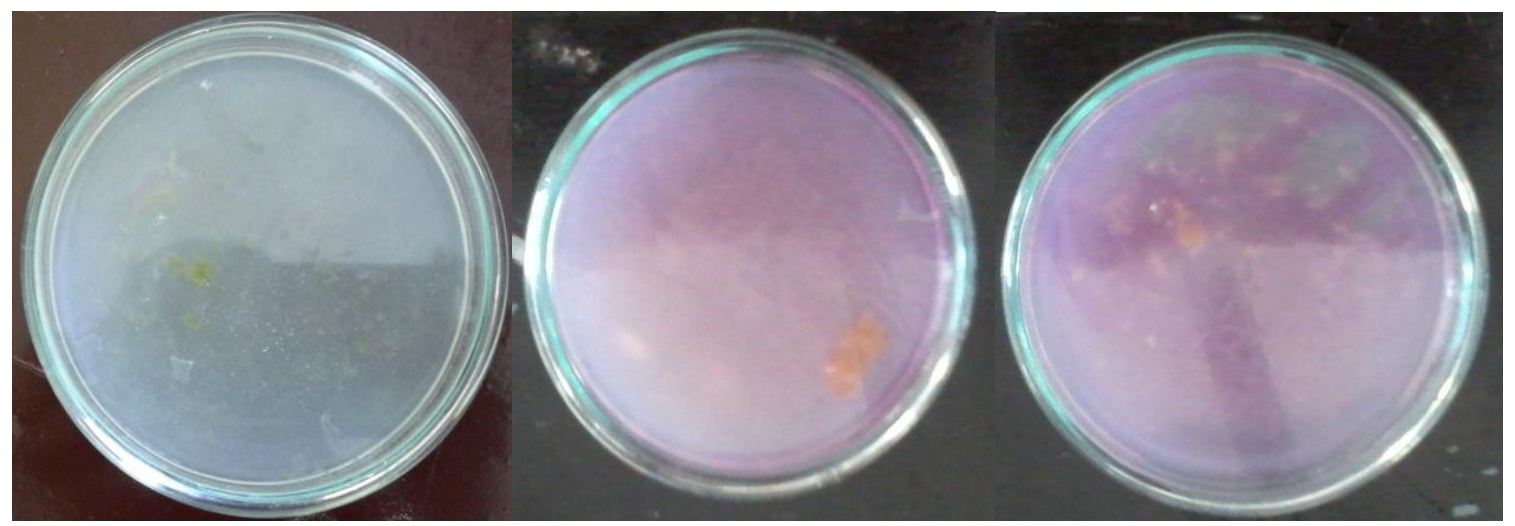

(a) Control

(b) Chaetoceros calcitrans

(c) Mixed algae

Fig. 1: Urea hydrolysis test with microalgal cultures.

Urea hydrolysis was done on bacteria using Christensen's agar medium (Hammad et al., 2013). In the present work urea test on microalgae was done using M342 agar medium. This urea hydrolysis test and urease test both are similar. The main aim is to check the breakdown of urea by urease enzyme. Urease test was done in broth and urea hydrolysis was done in agar medium.

\section{Urea tolerance level}

Chaetoceros calcitrans and mixed algal sample inoculated in urea of different concentration and the turbidity was observed OD was determined at $600 \mathrm{~nm}$ using UV Spectrophotometer (Fig. 2).

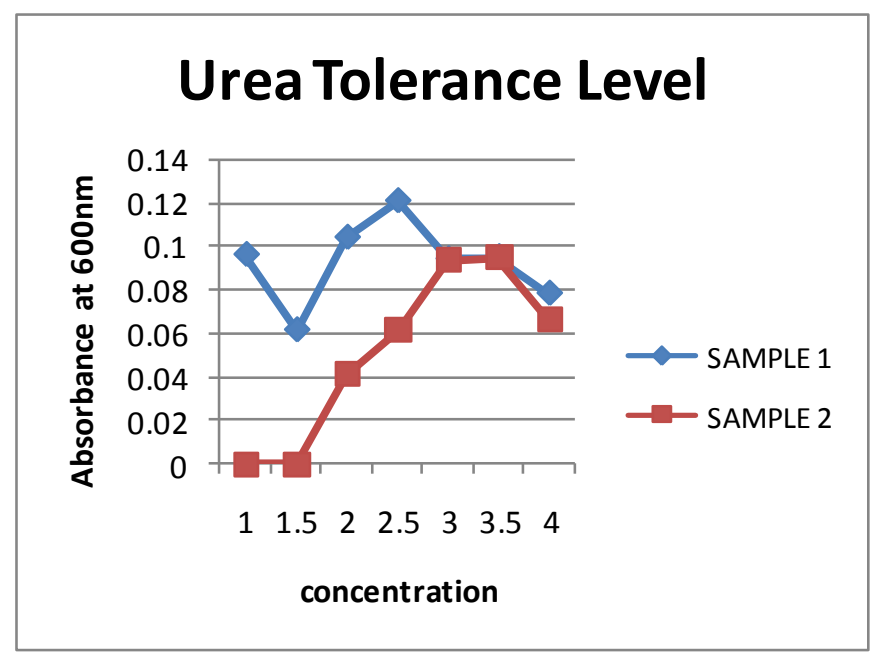

Fig. 2: Urea tolerance level shown by microalgae. Sample 1Chaetoceros calcitrans; Sample 2- Mixed algae.

Higher concentration of urea does not inhibit the algal growth (Anita et al., 1977). In the present work, urea tolerance level is higher in Chaetoceros calcitrans than the mixed algae sample.

\section{Biocement production}

Calcium carbonate precipitation was observed in both Chaetoceros calcitrans and mixed algae culture. Precipitation of calcium carbonate was more in mixed algae than the Chaetoceros calcitrans in 2 weeks time.

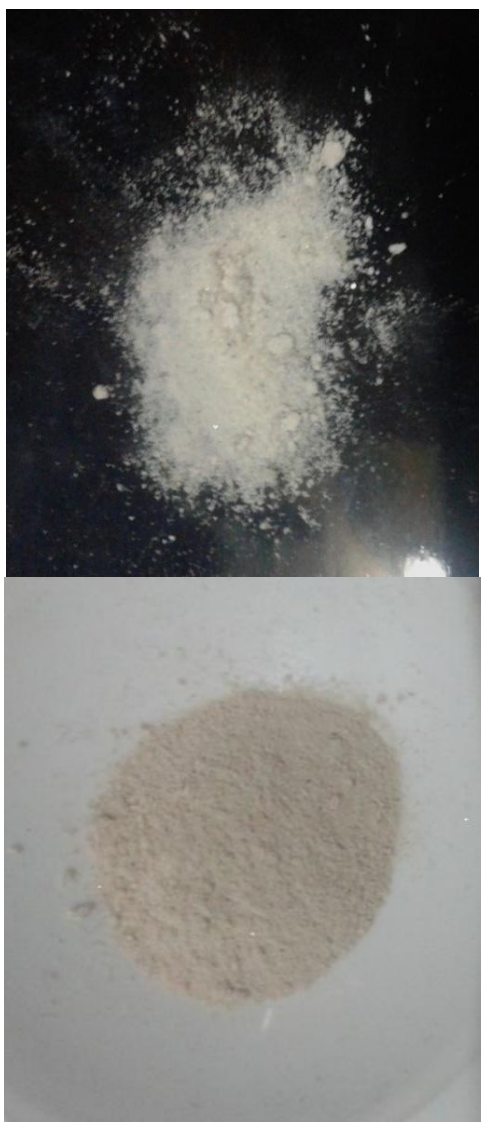

Fig. 3: Biocement produced by microalgae.

After two weeks of incubation calcium carbonate precipitate or Biocement is produced (Varalakshmi and Anchana Devi, 2014) used bacteria to produce calcium carbonate precipitate. 


\section{Characterisation of biocement by SEM}

Porous algae precipitate were studied using Scanning Electron Microscopic analysis (Niveditha et al., 2014) which showed that the precipitated crystals were bigger than $20 \mu \mathrm{m}$, formed clusters and more aggregated deposits with $50 \mu \mathrm{m}$. The calcium carbonate precipitate was less porous (Fig. 4). The characterization of biocement done using Scanning Electron Microscopy clearly showed agglomerates. The main element was detected as calcium.

\section{Applications of biocement}

Cracks in the tube were filled with biocement and hole in the tube also sealed with biocement. To check the binding capacity the biocement were made into bead to hold the string (Fig 5).

(a)

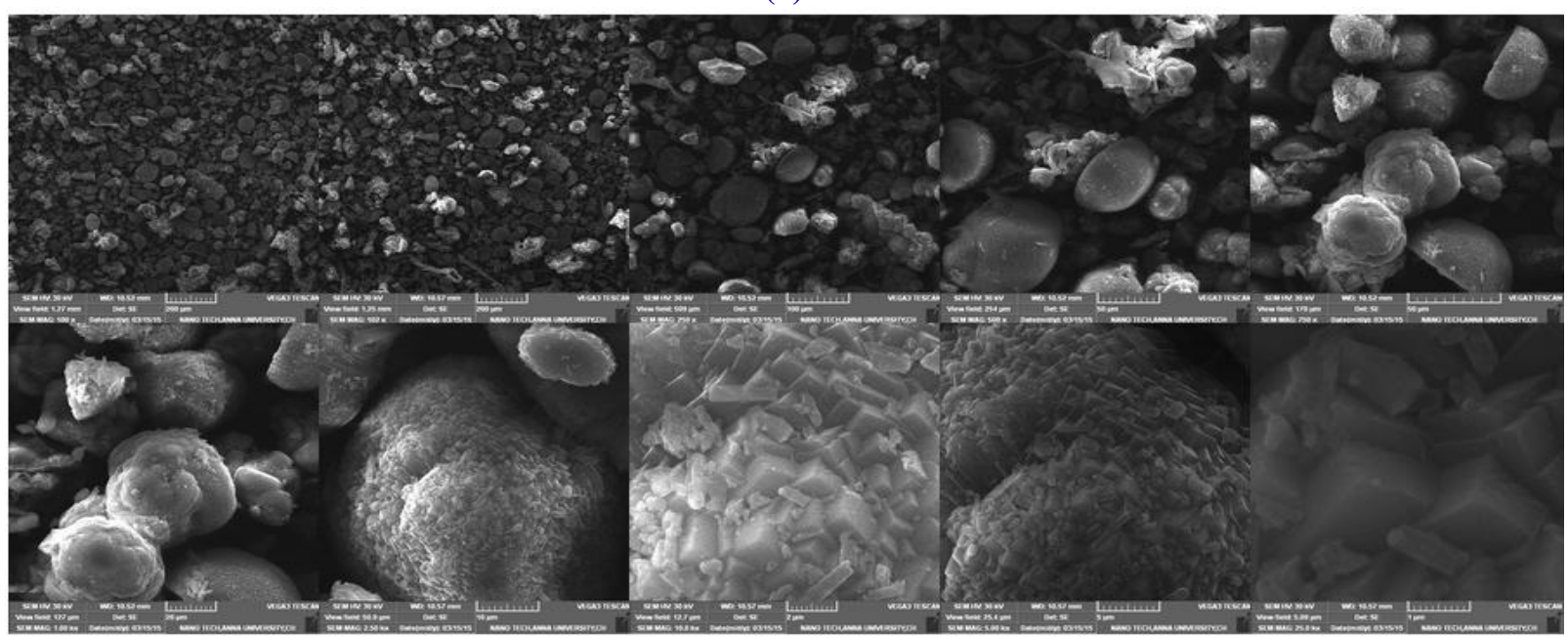

(b)

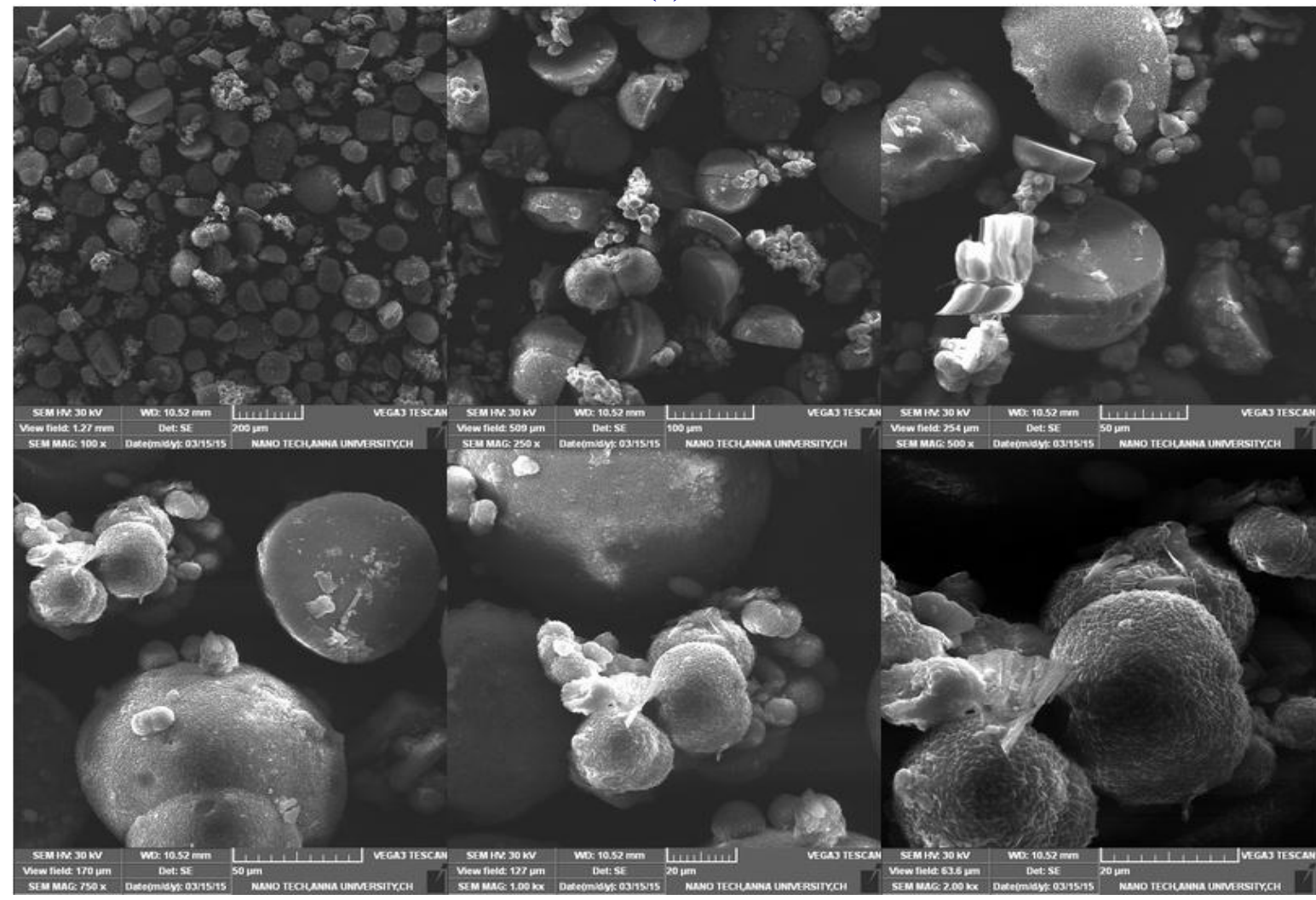

Fig. 5: The SEM micrographs of microalgae: (a) SEM micrographs of biocement of Chaetoceros calcitrans; (b) SEM micrographs of biocement of mixed algae. 


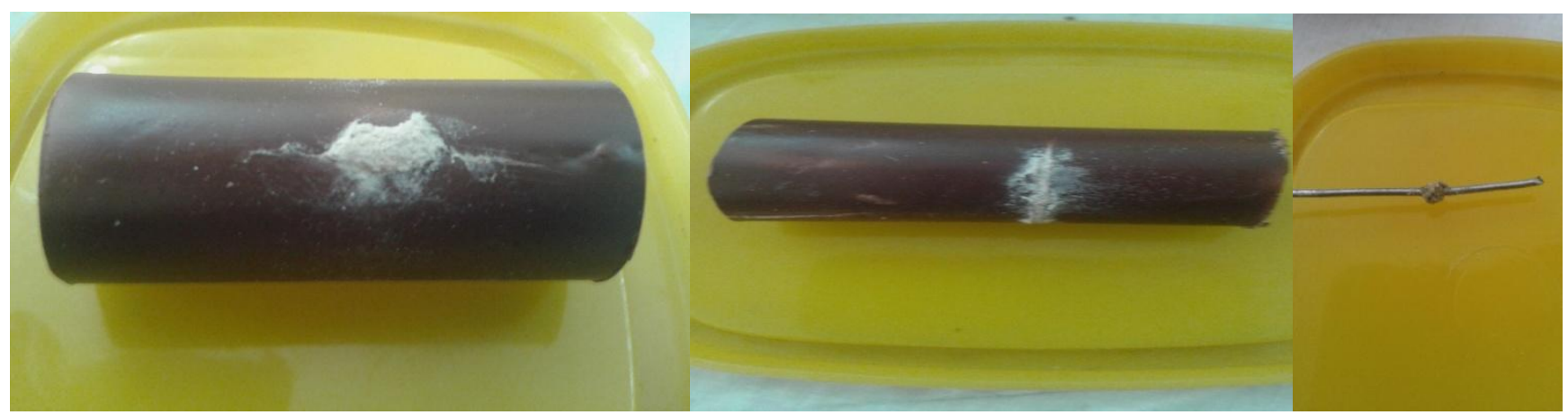

Fig. 5: Applications with biocement produced from microalgae.

\section{Conflict of interest statement}

Authors declare that they have no conflict of interest.

\section{References}

Anita, N.J., Berland, B.R., Bonin, D.J., Maestrini, S.Y., 1977 Effects of urea concentration in supporting growth of certain marine microplanktonic algae. Phycologia. 16(1), 105-111.

Banerjee, S., Hew, W.E., Khatoon, H., Shariff, M., Yusoff, F.M., 2011. Growth and proximate composition of tropical marine Chaetoceros calcitrans and Nannochloropsis oculata cultured outdoors and under laboratory conditions. Afr. J. Biotechnol. 10(8), 13751383.

Ghosh, P., Mandal, S., Pal, S., Bandyopadhyaya, G., Chattopadhyay, B.D., 2006. Development of bioconcrete material using an enrichment culture of novel thermophilic anaerobic bacteria. Ind. J. Exp. Biol. 44(4), 336-339.

Hammad, I.A., Talkhan, F.N., Zoheir, A.E., 2013. Urease activity and induction of calcium carbonate precipitation by Sporosarcina pasteurii NCIMB 8841. J. Appl. Sci. Res. 9, 1525-1533.
Ilavarasi, A., Mubarakali, D., Praveenkumar, R., Baldev, E., Thajuddin, N., 2011. Optimization of various growth media to freshwater microalgae for biomass production. Biotechnol. 10, 540-545.

Niveditha, C., Sarayu, K., Ramachandra Murthy, A., Ramesh Kumar, V., Iyer, N.R., 2014. Marine Algae for cement mortar strengthening. J. Civil Engg. Res. 4(2A), 23-25.

Patil, K.J., Mahajan, R. T., 2011. Enzyme profile of fresh water uncultured algae belonging to Bhusawal region, Maharashtra. J. Chemo Biosphere 1(2), 33-38.

Varalakshmi, Anchana Devi, 2014. Isolation and characterization of urease utilizing bacteria to produce biocement. IOSR J. Environ. Sci. Toxicol. Food Technol. $8,52-57$.

Yappert, M. C., DuPre, D.B., 1997. Complexometric titrations: Competition of complexing agents in the determination of water hardness with EDTA J. Chem. Educ. 74(12), 1422.

\section{How to cite this article:}

Jebamalar, J., Priya Iyer, 2016. Production of biocement from microalgae. Int. J. Curr. Res. Biosci. Plant Biol. 3(1), 122-126. doi: http://dx.doi.org/10.20546/ijcrbp.2016.301.013 